\title{
Gestational high-fat diet and bisphenol A exposure heightens mammary cancer risk
}

\author{
Yuet-Kin Leung1,2,3, Vinothini Govindarajah1,2, Ana Cheong1,2, Jennifer Veevers, 2,3, \\ Dan Song1,2, Robin Gear2,5, Xuegong Zhu1,2, Jun Ying1,2,3, Ady Kendler4, \\ Mario Medvedovic',2,3, Scott Belcher2,5,† and Shuk-Mei Ho1,2,3,6 \\ 1Department of Environmental Health, Cincinnati, Ohio, USA \\ ${ }^{2}$ Center for Environmental Genetics, University of Cincinnati College of Medicine, Cincinnati, Ohio, USA \\ ${ }^{3}$ Cincinnati Cancer Center, Cincinnati, Ohio, USA \\ 4Department of Pathology and Laboratory Medicine, University of Cincinnati College of Medicine, Cincinnati, Ohio, USA \\ ${ }^{5}$ Department of Pharmacology and Cell Biophysics, University of Cincinnati College of Medicine, Cincinnati, Ohio, USA \\ ${ }^{6}$ Cincinnati Veteran Affairs Hospital Medical Center, Cincinnati, Ohio, USA \\ ${ }^{\dagger}(\mathrm{S}$ Belcher is now at Department of Biological Sciences, Raleigh, North Carolina, USA)
}

Correspondence should be addressed to S-M Ho Email shuk-mei.ho@uc.edu

\begin{abstract}
In utero exposure to bisphenol A (BPA) increases mammary cancer susceptibility in offspring. High-fat diet is widely believed to be a risk factor of breast cancer. The objective of this study was to determine whether maternal exposure to BPA in addition to high-butterfat (HBF) intake during pregnancy further influences carcinogeninduced mammary cancer risk in offspring, and its dose-response curve. In this study, we found that gestational HBF intake in addition to a low-dose BPA $(25 \mu \mathrm{g} / \mathrm{kg} \mathrm{BW} /$ day) exposure increased mammary tumor incidence in a 50-day-of-age chemical carcinogen administration model and altered mammary gland morphology in offspring in a nonmonotonic manner, while shortening tumor-free survival time compared with the HBF-alone group. In utero HBF and BPA exposure elicited differential effects at the gene level in PND21 mammary glands through DNA methylation, compared with HBF intake in the absence of BPA. Top HBF + BPA-dysregulated genes (ALDH1B1, ASTL, CA7, CPLX4, KCNV2, MAGEE2 and TUBA3E) are associated with poor overall survival in the Cancer Genomic Atlas (TCGA) human breast cancer cohort $(n=1082)$. Furthermore, the prognostic power of the identified genes was further enhanced in the survival analysis of Caucasian patients with estrogen receptor-positive tumors. In conclusion, concurrent HBF dietary and a low-dose BPA exposure during pregnancy increases mammary tumor incidence in offspring, accompanied by alterations in mammary gland development and gene expression, and possibly through epigenetic reprogramming.
\end{abstract}

\author{
Key Words \\ - breast cancer \\ - developmental origin of \\ health and disease (DOHaD) \\ - RNA-seq \\ - transcriptomics \\ - DNA methylation \\ - patient survival \\ - TCGA \\ - windows of susceptibility \\ - in utero exposure \\ - bisphenol A \\ - high-butter fat diet \\ - non-monotonic response
}

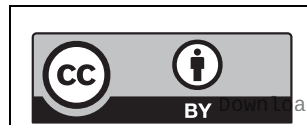

This work is licensed under a Creative Commons Attribution 3.0 Unported License. 


\section{Introduction}

Breast cancer is a major global public health problem and effective prevention strategies are needed to combat the disease, most desirably at the primary prevention level (Hanf \& Gonder 2005, Fabian et al. 2015). In addition to family history, other risk factors including hormonal and environmental factors, particularly nutrition, have been identified to be major contributors in the etiology of breast cancer (Peto 2001, Holmes \& Willett 2004, Adebamowo et al. 2005, Teegarden et al. 2012). For example, exposure to Western lifestyles dramatically increases breast cancer incidence in Asian immigrants in the United States (US) during their lifetime and in their offspring over several generations (Buell 1973, Ziegler et al. 1993). Maternal exposures to endocrinedisrupting chemicals (EDCs) and certain dietary factors during pregnancy have been reported to be associated with increased mammary tumorigenesis among female offspring (Prentice et al. 2006, Durando et al. 2007, Moral et al. 2008, Doherty et al. 2010, Soto et al. 2013). However, cohort and human case-control studies have generated conflicting reports regarding the effect of high-fat intake on adult breast cancer risk (Hulka 1989, Willett et al. 1992, Hunter et al. 1996, Martin et al. 2011), partly due to differences in fat/dietary composition, and study design, including exposure window. For example, consumption of animal fat, consisting mainly of saturated fatty acids, is associated with increased risk of breast cancer in some studies (Cho et al. 2003, Gonzalez \& Riboli 2010) but not in others (Lof et al. 2007, Key et al. 2011, Park et al. 2012). The development of rodent models have proved critical to assess the effects of single and/or multiple exposures on susceptible windows of mammary gland development and in the subsequent identification of factors relevant for breast cancer prevention in humans.

The mammary gland has been shown to be particularly sensitive during early development, both to dietary fatty acids and EDCs such as bisphenol A (BPA), perhaps because extensive programming of the mammary gland occurs during fetal life (Hilakivi-Clarke et al. 1995, 1996, 1999, 2002, Durando et al. 2007, Moral et al. 2008, Lo et al. 2009, Doherty et al. 2010, MacLennan \& Ma 2010, Soto et al. 2013). High-fat intake during pregnancy has been shown to increase offspring' mammary cancer risk by altering mammary gland development, mainly by increasing the number of terminal end buds (TEBs) (Hilakivi-Clarke et al. 1997, de Assis et al. 2006), the purported target structures of malignant transformation (Russo et al. 1983, Welsch 1985, Russo \& Russo 1996a,b). Similarly in rodent models,
BPA has been reported to alter the development of the mammary gland suggesting the possibility of increased susceptibility to mammary tumorigenesis (Markey et al. 2001, Munoz-de-Toro et al. 2005, Durando et al. 2007). Using the 7,12-dimethylbenz(a)anthracene (DMBA)induced mammary carcinogenesis Sprague-Dawley (SD) rat model, Russo and coworkers (Betancourt et al. 2010) reported that a prenatal BPA dose of either 25 or $250 \mu \mathrm{g} /$ $\mathrm{kg}$ body weight (BW)/day by itself had no tumorigenic effect after DMBA exposure on postnatal day (PND)50. However, when DMBA was administered at PND100 following prenatal BPA exposure at $250 \mu \mathrm{g} / \mathrm{kg} \mathrm{BW} /$ day, the EDC exposure resulted in a significantly increased number of terminal ducts (Moral et al. 2008) as well as a higher incidence of mammary tumors (Betancourt et al. 2010). As the epigenome is most susceptible to perturbations in early development, the adverse effects of in utero exposures on adult health are likely mediated by epigenetic dysregulation of gene expression (Perera \& Herbstman 2011). Indeed, a high-fat- or ethinylestradiolsupplemented maternal diet has been shown to increase mammary cancer risk in several generations of offspring and is associated with changes in the DNA methylation machinery and methylation patterns in mammary tissue (de Assis et al. 2012).

We are not aware of any previous studies that have investigated the impact of maternal consumption of a high-butterfat (HBF) diet together with exposure to low-dose BPA on mammary cancer risk of offspring. The present study aimed to test the hypothesis that maternal exposure to low, environmentally relevant doses (2.5-2500 $\mu \mathrm{g} / \mathrm{kg}$ BW/day) of BPA, in addition to HBF intake during pregnancy leads to increased incidence of mammary cancer in offspring. According to our previous study, we chose butter as the source of high fat $39 \%$ kcal) to mimic a key fat component in the Western diet, and which does not promote obesity in our animal model (Medvedovic et al. 2009). Our results indicate that concurrent exposure of dams to a HBF diet and BPA at $25 \mu \mathrm{g} / \mathrm{kgBW} /$ day dose level during pregnancy increases mammary tumor incidence in offspring treated with DMBA on PND50, accompanied by alterations in mammary gland development. Furthermore, in utero HBF and BPA exposure elicited differential effects at the gene level in prepubertal mammary glands through DNA methylation, compared with HBF in the absence of BPA. A signature of top dysregulated genes was subsequently found to be associated with poor overall survival in populations of

Published by Bioscientifica Ltd 
breast cancer patients from The Cancer Genomic Atlas (TCGA). These findings highlight the importance of future studies to address maternal diets as modifiers of susceptibility to in utero exposure to environmental agents for devising new strategies to reduce breast cancer risk.

\section{Materials and methods}

\section{Animals}

Female, virgin SD rats at $\sim 7$ weeks of age were obtained from Taconic Farms (Germantown, NY, USA). Animals were housed individually in a temperature- and humiditycontrolled environment with a 12-h light-darkness cycle, in the AAALAC-approved University of Cincinnati animal facility. All rats were provided food and filtered water ad libitum, and animals were housed on sani-chips bedding and maintained in an environment under controlled endocrine-disrupting chemical (EDC) exposures (Thigpen et al. 2013, Martinez et al. 2015). All animal procedures were approved by the University of Cincinnati Institutional Animal Care and Use Committee, and experiments were performed following the guidelines of the National Institutes of Health for the proper and humane use of animals in biomedical research.

\section{Experimental design and mammary tumorigenesis}

Female SD rats (7-9 weeks old) were randomized into 6 groups $(n=11)$. After two weeks (acclimation) of experimental diet group exposure, female rats were bred with male SD rats ( $\sim 3$ months of age). During mating and throughout gestation, dams were fed either a control AIN-93G diet (10\% kcal from butterfat) or a modified AIN-93G high-butterfat diet (39\% kcal from butterfat), in the presence or absence of BPA (SigmaAldrich) at various environmentally relevant doses: 2.5, 25,250 or $2500 \mu \mathrm{g} / \mathrm{kg} \mathrm{BW} /$ day. Diets were controlled for caloric content, vitamins, salts and protein, but varied in fat and carbohydrate content. After birth, dams and offspring were maintained on control AIN-93G diet for the duration of the experiment. Litters were weighed weekly until killed. The date of vaginal opening was recorded as an indication of reaching sexual maturity. At PND50, one female offspring per litter per group was treated with a single oral dose $(20 \mathrm{mg} / \mathrm{kgBW})$ of DMBA (Thermo Fisher Scientific) to induce mammary cancer, and another littermate was given corn oil (Sigma-Aldrich) as a control. Animals were palpated weekly to monitor tumor development. Tumor size was measured using a caliper and tumor volume was calculated. All pups were killed at PND140, or when tumor burden exceeded $10 \%$ of total BW. Time to first tumor appearance (latency), the number of animals with palpable tumors (incidence) and the number of tumors per animal (multiplicity) were determined. The origin of the tumor was confirmed by a clinical pathologist (AK). Serum hormone levels of $17 \beta$-estradiol (Calbiotech, Spring Valley, CA, USA), progesterone (IBL, Minneapolis, MN, USA), leptin (EMD Millipore) and adiponectin (EMD Millipore) at PND21 and 50 were measured using ELISA-based assays. A schematic diagram summarizing the experimental design of this study is presented in Fig. 1.

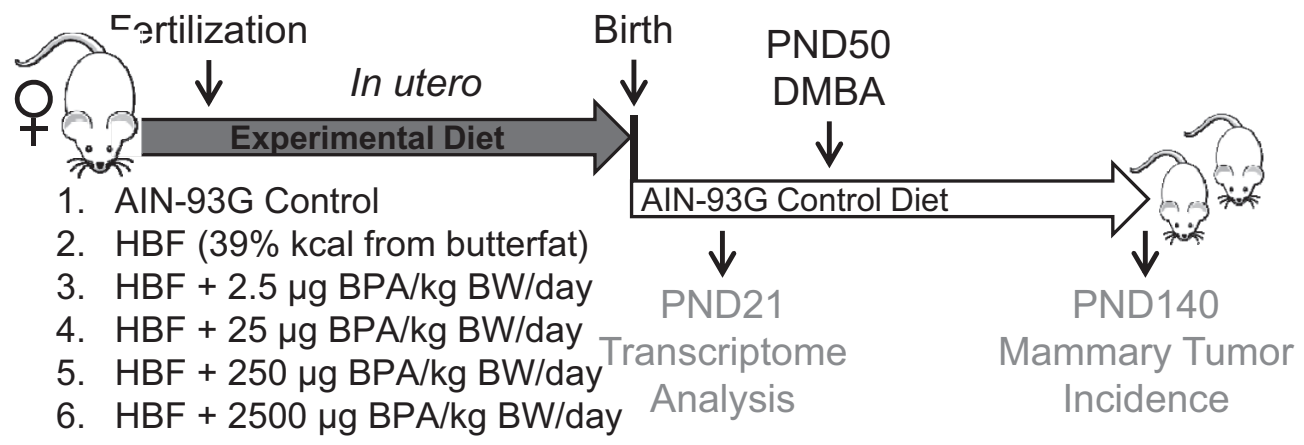

Figure 1

Schematic diagram of the experimental design. Female SD rats (7-9 weeks old) were randomized into 6 groups ( $n=11$ litter/group, one offspring/litter). During mating and throughout gestation, dams were fed a control AIN-93G diet or a modified AIN-93G high-butterfat (HBF) diet in the presence or absence of bisphenol A (BPA) at various concentrations ( $\mu \mathrm{g} / \mathrm{kg}$ BW (body weight)/day). After birth, dams and offspring were maintained on an AIN-93G diet for the duration of the experiment. Pups were weaned at PND21 and one female offspring per litter was killed for mammary gland transcriptome analysis. At PND50, one female offspring from each dietary group was treated with a single oral dose ( $20 \mathrm{mg} / \mathrm{kg} \mathrm{BW})$ of DMBA to induce mammary cancer. All pups were killed at PND140 for analysis and determination of mammary tumor incidence. 


\section{Whole mount and morphometric analysis}

The fourth abdominal mammary gland from PND21 female pups was prepared as whole mount for morphological analysis according to an established protocol (Russo $\&$ Russo 1978). The total number of terminal end buds (TEBs) was evaluated by counting individual structures under a dissection microscope.

\section{Laser capture microdissection}

PND21 mammary glands from female offspring $(n=5 \mathrm{~L} /$ group, one offspring/L) fed a HBF diet and a HBF diet with $25 \mu \mathrm{gBP} / \mathrm{kgBW} /$ day were chosen for laser capture microdissection (LCM) according to our published protocol (Zhu et al. 2004). Briefly, mammary glands were first cryosectioned with 10 micron thick, hematoxylinstained and dried for microdissection. Multiple sections ( 5) per mammary gland were microdissected using an Arcturus Veritas Laser Capture Microdissection System (Thermo Scientific).

\section{RNA sequencing}

Total RNA was extracted from LCM samples using a Qiagen RNeasy Lipid kit (Qiagen). The RNA quality and quantity were assessed using Agilent Bioanalyzer (Agilent) and NanoDrop ND-1000 spectrophotometer (Thermo Scientific), respectively. RNA libraries were prepared according to manufacturer's protocol of TruSeq RNA sample preparation kit (Illumina, San Diego, CA, USA) and were sequenced with Genome Analyzer II sequencing system in the Genomics, Epigenomics and Sequencing Core at the University of Cincinnati. Analysis of gene expression was performed with our standard pipeline (Govindarajah et al. 2016). Differentially expressed genes of the $\mathrm{HBF}+\mathrm{BPA}$ group were selected based on $P<0.05$ and a fold-change greater than 2 , when compared with the HBF-alone group. Functional enrichment analysis of differentially expressed genes was performed using the knowledge-based Ingenuity Pathways Analysis (IPA) (Qiagen, www.qiagen.com/ingenuity). RNA-seq data were deposited in the NCBI Gene Expression Omnibus database with accession number GSE73604.

\section{Real-time PCR (qPCR) analysis}

Total RNA extracted from microdissected samples was amplified using the RiboAmp HS PLUS RNA Amplification kit (Applied Bisosytems) according to the manufacturer's protocol. RNA expression was semi-quantified by SYBR GreenER (Thermo Fisher Scientific) using the 7900HT Fast Real-time PCR System (Thermo Fisher Scientific). Primer sequences are listed in Supplementary Table 1 (see section on supplementary data given at the end of this article). The target gene expression was normalized with endogenous Rpl19 level, and the relative change in transcript level was calculated using the delta-delta-CT method (Livak \& Schmittgen 2001).

\section{Bisulfite sequencing analysis}

Sections from PND21 mammary glands in female offspring ( $n=4-6$ litter/group, one offspring/litter) were used for genomic DNA (gDNA) extraction and for bisulfite sequencing analysis according to our published protocol (Zhu et al. 2004).

\section{TCGA survival analysis}

RNA-seq analysis (RNA-seqV2) of The Cancer Genomic Atlas (TCGA) breast cancer samples as well as patient clinical data were downloaded (http://cancergenome. nih.gov) on 3/8/2016. The original TCGA breast cancer data set consists of RNA-seq data from 1215 samples. Data on tumor adjacent normal (113), metastatic tumor (7) and male breast cancer samples (12) were excluded. One sample was discarded due to lack of survival data. In this study, only 1082 female samples (746 Caucasian, 180 African American, 61 Asian, 1 American Indian or Alaska Native and 94 unknown) with ER status (795 ER+, 237 ER- and 50 indeterminate or N/A) were used for survival analyses. Normalized data of seven genes identified and verified in the LCM study (ALDH1B1, ASTL, CA7 (official gene symbol for carbonic anhydrase VII in human), CPLX4, KCNV2, MAGEE2 and TUBA3E (equivalent to Tuba3A in rat)) were variance stabilizing-transformed before hierarchical clustering with complete linkage based on the Euclidean distance between genes was performed to dichotomize the cohort into two groups. Survival data including days-to-last follow-up and days-to-death were extracted from TCGA clinical data. Overall survival between two groups was analyzed by Kaplan-Meier plot with log-rank test, and Cox proportional hazard models (with age at initial pathologic diagnosis adjusted) were used to analyze time to death. All analyses were carried out using survival package in $\mathrm{R}$ (http://www.r-project. org). To further determine the characteristics between the two groups, clinical features including age, estrogen receptor status, progesterone receptor status, cancer stage,

Published by Bioscientifica Ltd. 
cancer recurrence as well as lymph node positivity were compared using Student $t$-test (continuous variables) or Pearson's chi square test with contingency tables (categorical variables). The tests were conducted using GraphPad Prism 5.0.

\section{Statistical analysis}

Gene expression and bisulfite sequencing analyses were performed using GraphPad Prism 5.0. For gene expression analyses, data were expressed as mean \pm standard error of mean (s.E.M.) and analyzed by Student $t$-test and post hoc Mann-Whitney test. Bisulfite sequencing data were expressed as \% methylation and analyzed using two-way ANOVA and Bonferroni post-test. $P<0.05$ was considered as statistically significant when compared between and among groups.

\section{Results}

\section{Gestational high-fat intake in addition to bisphenol A exposure increases mammary tumor incidence and effects mammary gland morphology}

To test our hypothesis that maternal exposure to BPA in addition to HBF intake during pregnancy leads to increased incidence of mammary cancer in offspring, we fed female SD rats (F0) with a modified AIN-93G HBF diet containing 39\% kcal from butterfat, during mating and throughout gestation, in the presence and absence of BPA exposure (Fig. 1). To evaluate dose-response, we treated dams with $0,2.5,25,250$ or $2500 \mu \mathrm{g}$ BPA $/ \mathrm{kg}$ body weight (BW) everyday starting from 2 weeks before conception until the end of the gestational period. Offspring were maintained on control AIN-93G diet for the duration of the experiment. In utero exposure to all BPA doses while fed a HBF diet did not affect litter size of the dams or significantly alter the body weights of 2-, 7-, 14-, 21-, 35- and 50-day-old female offspring when compared with either the HBF-alone or control diet groups (data not shown).

Similarly, estrous cyclicity of adult female offspring (data not shown) and serum concentrations of $17 \beta$-estradiol, progesterone, leptin and adiponectin in PND21 and PND50 female offspring were not significantly different among control and HBF diet groups (Supplementary Table 3). Interestingly, exposure to HBF plus $2.5 \mu \mathrm{g} / \mathrm{kgBW} /$ day BPA significantly delayed (by $\sim 1.5$ days) the onset of puberty in the female offspring when compared with the HBF-alone group, as determined by vaginal opening (Supplementary Table 3). Maternal exposure to a HBF diet alone, however, did not alter the time to vaginal opening in offspring when compared with the control diet group.

Using a well-established chemically induced mammary cancer model, we treated female offspring with the carcinogen, DMBA, on PND50 (Russo et al. 1979, Heffelfinger et al. 2003). Using palpable tumor as the endpoint, we found no significant difference in average time to first tumor appearance (i.e. latency) (Supplementary Fig. 1A), number of palpable tumors (i.e. multiplicity) (Supplementary Fig. 1B) or tumor volume (data not shown) in DMBA-treated rats gestationally exposed to control AIN-93G or HBF diet groups (Supplementary Fig. 1A and B). In contrast, offspring of dams exposed to $\mathrm{HBF}$ and $25 \mu \mathrm{g} / \mathrm{kg}$ BW/day BPA during pregnancy had significantly higher mammary tumor incidence (90\%) compared with HBF-alone controls $(45.5 \%) \quad(P<0.043)$ (Fig. 2A) as well as a significantly shorter tumor-free survival time ( $P=0.0422$ ) (Fig. $2 \mathrm{~B})$. Offspring exposed to a control diet with $10 \%$ kcal butterfat showed no significant difference in mammary tumor incidence in the absence vs presence of $25 \mu \mathrm{g} / \mathrm{kg} \mathrm{BW} /$ day BPA (data not shown).

High-fat intake during pregnancy has been shown to increase offspring' mammary cancer risk by altering mammary gland development, mainly by increasing the number of terminal end buds (TEBs) (Hilakivi-Clarke et al. 1997). We examined the number of mammary gland TEBs on PND21. In contrast to published results using a corn oil high-fat diet (de Assis et al. 2012), our HBF group did not show any significant effect on TEB number when compared with the control AIN-93G diet group (Fig. 2C). However, when dams were gestationally exposed to $25 \mu \mathrm{g}$ or $250 \mathrm{BPA} / \mathrm{kgBW} /$ day in addition to a HBF diet, the number of TEBs was significantly increased in the mammary glands of offspring at PND21 (Fig. 2C and D).

\section{Transcriptome analysis identifies HBFBFBPA-regulated genes associated with cancer-related signaling}

To gain insight into how gestational $\mathrm{HBF}$ intake in addition to BPA exposure $(25 \mu \mathrm{g} / \mathrm{kgBW} /$ day $)$ modulates mammary tumor incidence in offspring, we performed genome-wide transcription analysis on laser capture microdissected (LCM) epithelia of PND21 mammary glands. Using this approach, we identified 504 differentially expressed genes $(P<0.05)$ between the HBF-alone and $\mathrm{HBF}+\mathrm{BPA}(25 \mu \mathrm{g} / \mathrm{kg} \mathrm{BW} /$ day $)$ diet groups. Hierarchical clustering clearly segregated the

Published by Bioscientifica Ltc. 
A

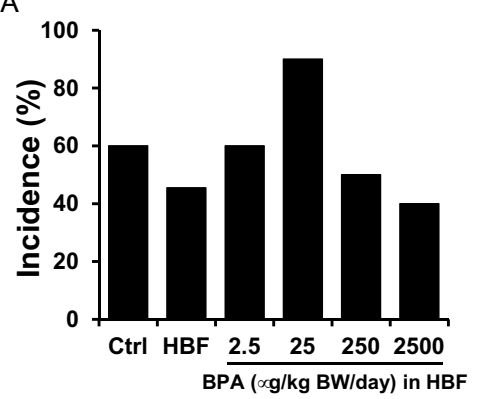

B

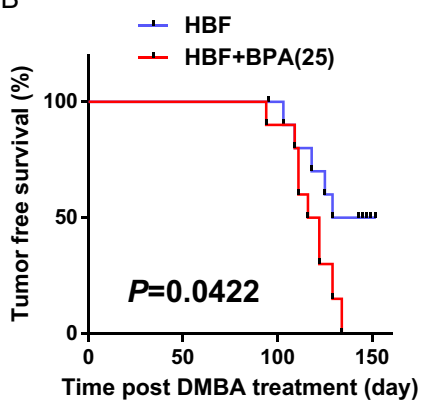

C

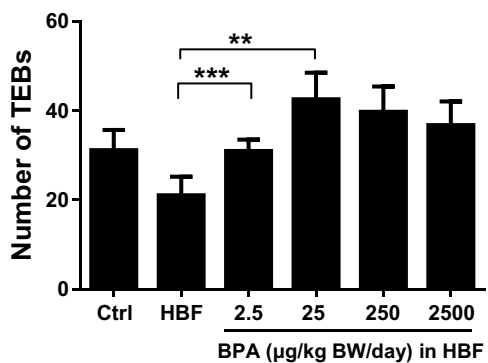

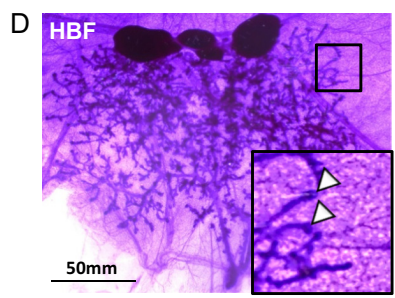

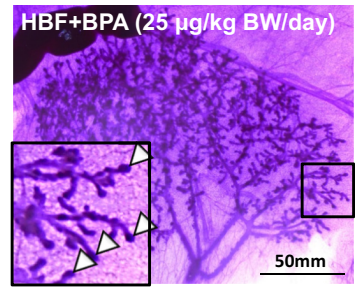

Figure 2

Gestational exposure to high butterfat and bisphenol A increases mammary tumor incidence and effects mammary gland morphology. (A) Tumor incidence (percentage of rats that developed at least one tumor) at PND140, in DMBA-treated offspring fed a control (AIN-93G) diet (Ctrl), or a high-butterfat (HBF) diet in the presence or absence of bisphenol A (BPA) at various concentrations. (B) Time (days) post DMBA treatment to first palpable tumor in HBF-alone vs HBF+BPA25 ( $\mu \mathrm{g} / \mathrm{kg}$ BW/day) groups (log-rank test, $P=0.0422$ ). (C) Number of terminal end buds (TEBs) in PND21 mammary glands, in offspring fed a Ctrl, or a HBF diet in the presence or absence of BPA at various concentrations. Data are expressed as mean \pm S.E.M. $* * P<0.01, * * * P<0.001$ vs HBF, two-way ANOVA. (D) Representative whole mount images of PND21 mammary glands showing TEBs in offspring fed a $\mathrm{HBF}$ diet (left) and a HBF diet with $25 \mu \mathrm{g} / \mathrm{kg} \mathrm{BW} /$ day BPA (right). Scale bar: $50 \mathrm{~mm}$. Corner inset is a high magnification view of boxed area. Arrowheads mark the location of TEBs.

differentially expressed genes into two groups, $\mathrm{HBF}$ and $\mathrm{HBF}+\mathrm{BPA} 25(\mu \mathrm{g} / \mathrm{kg} \mathrm{BW} /$ day) (Fig. 3A).

To identify biological processes related to the identified dietary exposure-associated genes, we performed pathway analysis by interrogating the knowledge-based Ingenuity Pathway Analysis (IPA) database (Qiagen, www.qiagen. com/ingenuity). Interestingly, the top two networks were found to be cancer related, including 'Cancer, Cellular development, Embryonic development' and 'Gene expression, Cancer, and Organismal injury and Abnormalities'. There were 25 genes involved in each network. One was associated with extracellular signalregulated kinase (ERK) rapid signaling (Fig. 3B) and the other was related to androgen receptor (AR, Fig. 3C). When these networks were merged, AR appears to be the key node for those two cancer-related networks (Fig. 3D).

Follow-up analysis of the gene expression array study was then performed using qRT-PCR for the ten most upregulated (Calcb, Msl3l2, Aldh1b1, Spert, Astl, Magee2, Tuba3a, LOC052614, Cplx4 and Kcnv2) and ten most downregulated (Olr1229, Olr791, Fam46d, Olr788, Olr984, Olr750, Olr51, Ccr9, Car7 and Olr830) genes (Table 1). Notably, there was a panel of seven olfactory receptors (Olr) found to be downregulated by BPA exposure. Of the twenty differentially expressed genes, we found 12 genes (Aldh1b1, Astl, Cplx4, Kcnv2, LOC502684, Magee2, Tuba3a, Car7, Olr788, Olr830, Olr791 and Olr1229) were differentially expressed in the amplified LCM samples using qPCR analysis (Supplementary Fig. 2).

\section{In utero HBFBFBPA exposure dysregulated gene expression in PND21 mammary glands through DNA methylation}

We next investigated whether the dysregulation of genes in the mammary glands of $\mathrm{HBF}+\mathrm{BPA}$ offspring was associated with aberrant epigenetic regulation. The most common epigenetic alteration is methylation of cytosine in CpG dinucleotides in a gene's promoter region, resulting in alterations of gene expression. Thus, we first checked whether a putative CpG island could be found near the transcription start site of each gene using the rat genome database from The University of California Santa Cruz (RGSC 5.0/rn5) (https://genome.ucsc.edu/cgi-bin/ hgGateway). Six of the top upregulated genes (Msl3l2, Aldh1b1, Astl, LOC502684, Cplx4 and Kcnv2) showed at least one CpG island within their gene locus (Table 1). In contrast, only one gene of the top ten downregulated 
A

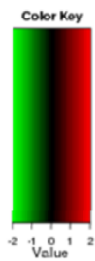

B

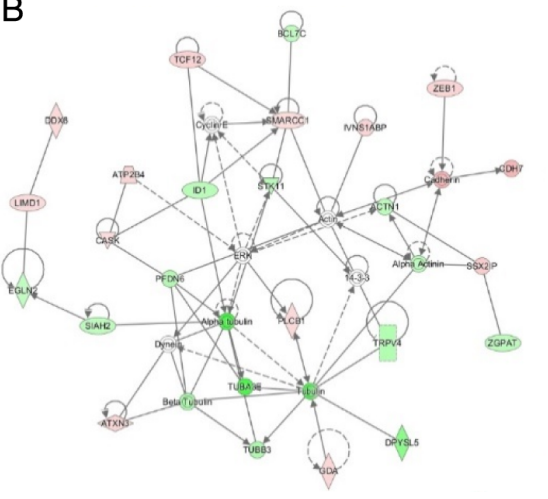

C

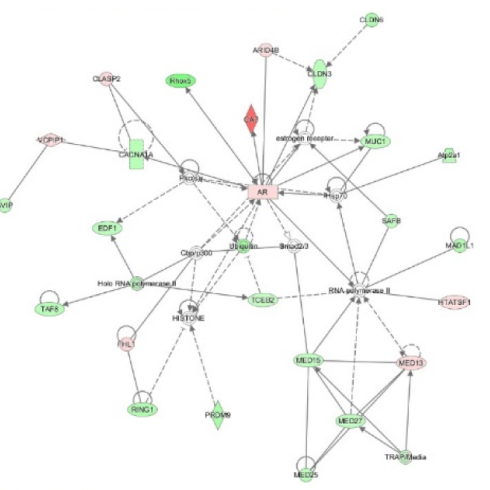

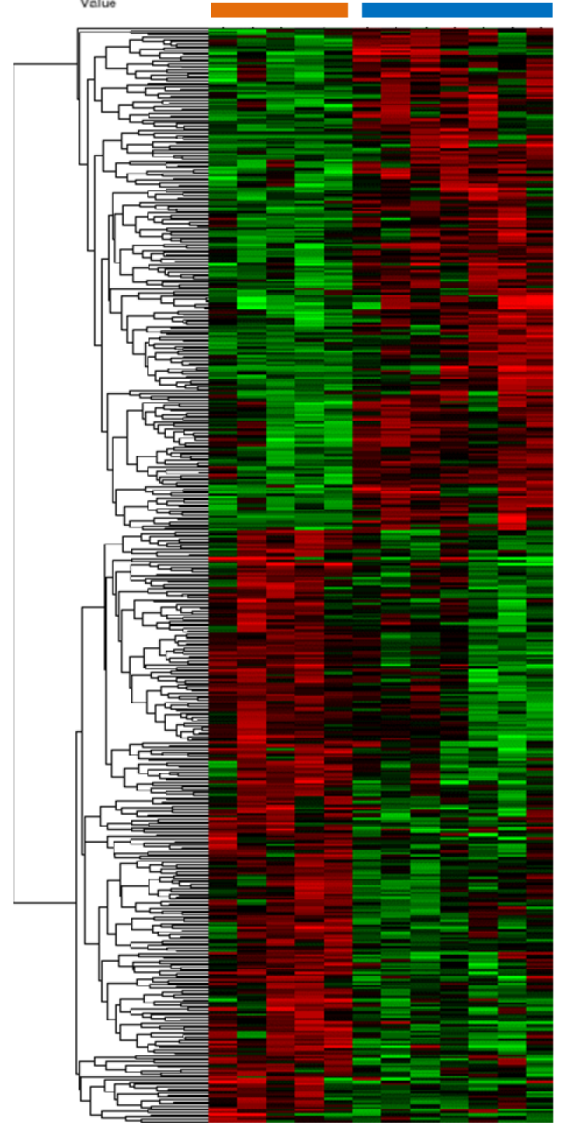

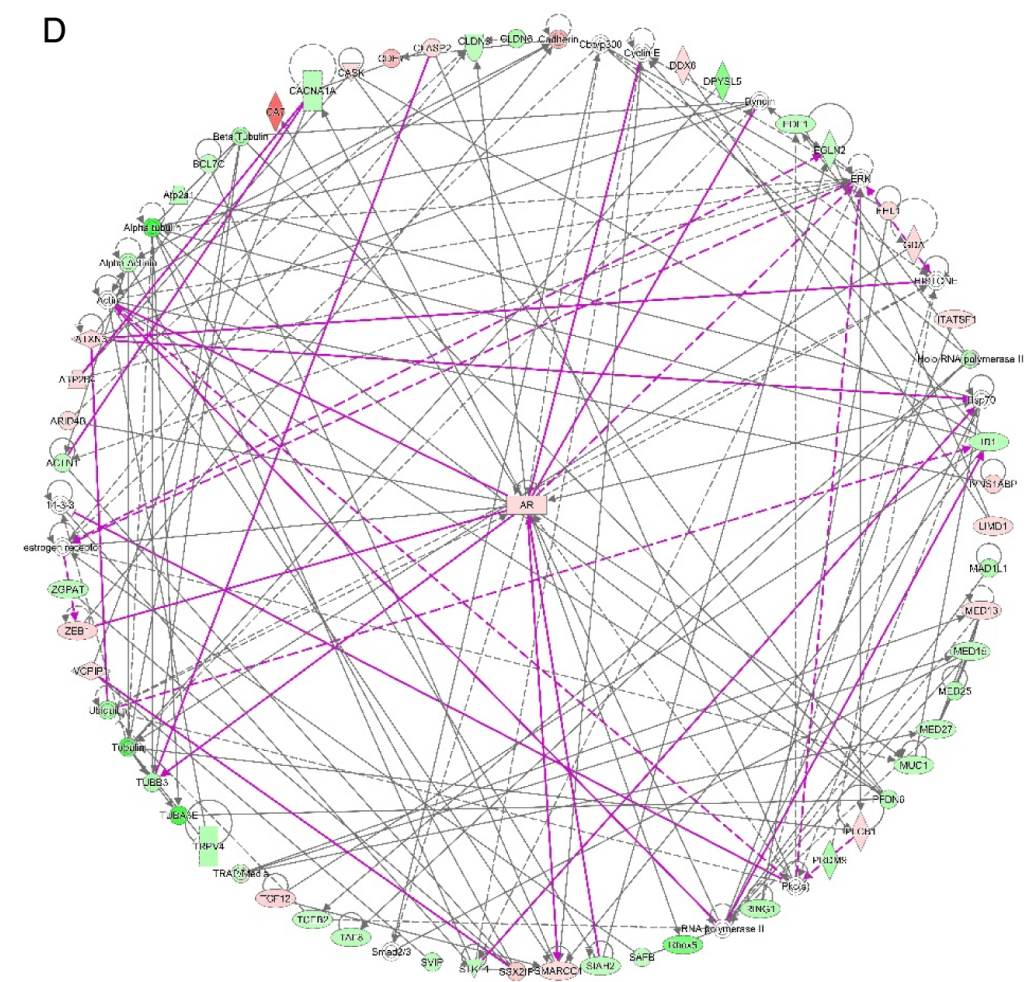

Figure 3

Transcriptome analysis identifies high butterfat intake and bisphenol A exposure-regulated genes associated with cancer-related signaling. (A) Hierarchical clustering analysis of 504 genes with $P<0.05$ from genome-wide transcription analysis of laser capture microdissected epithelia of PND21 mammary glands from offspring fed a high butterfat (HBF) diet vs a HBF diet with $25 \mu \mathrm{g} / \mathrm{kg}$ BW/day bisphenol A (BPA). Using an unbiased gene clustering method, the heat map shows that differential genes are clearly segregated between samples into two distinct groups. Ingenuity pathway analysis of the 504 genes identified two cancer-related networks associated with the HBF+BPA vs HBF-alone group: (B) extracellular signal-regulated kinase (ERK) rapid signaling and (C) androgen receptor (AR) signaling. (D) Merging of these networks identified AR to be the key node. Green represents low expression; red represents high expression.

genes, Car7, has a putative CpG island next to their 5' regulatory region (Table 1 ).

We then selected Car7 (Supplementary Fig. 3), and Kcnv2 (Supplementary Fig. 4), the only upregulated gene with a CpG island in close proximity to its regulatory region, for bisulfite sequencing analyses. As shown in Fig. 4A, significant hypermethylation was observed in the CpG island of Car7 in the BPA-exposed group when compared with the control group $(P<0.0001$, twoway ANOVA). In contrast, the level of methylation in the CpG island of Kcnv2 was significantly $(P=0.0068$, two-way ANOVA) reduced after in utero exposure to BPA $(25 \mu \mathrm{g} / \mathrm{kgBW} /$ day) (Fig. 4B). These methylation changes were inversely correlated with the changes 
Table 1 Top differentially expressed genes in mammary glands of offspring gestationally exposed to highbutterfat \pm bisphenol A.

\begin{tabular}{|c|c|c|c|c|}
\hline \multirow[b]{2}{*}{ Gene symbol } & \multirow[b]{2}{*}{ Gene name } & \multirow[b]{2}{*}{ Log 2 fold change } & \multicolumn{2}{|c|}{ Putative regulatory CpG islandc } \\
\hline & & & Presence & Location \\
\hline \multicolumn{5}{|c|}{ Upregulated genes } \\
\hline Calcba & Calcitonin-related polypeptide, beta & 6.6 & No & Not applicable \\
\hline$M s / 3 / 2^{a}$ & Male-specific lethal 3-like 2 & 5.5 & Yes & Exon 2 \\
\hline Aldh1b1a & $\begin{array}{l}\text { Aldehyde dehydrogenase } 1 \text { family, } \\
\text { member B1 }\end{array}$ & 5.0 & Yes & 5' promoter; TSS; Exon 1 \\
\hline Sperta & Spermatid associated & 4.8 & No & Not applicable \\
\hline Ast/a & $\begin{array}{l}\text { Astacin-like metallendopeptidase } \\
\text { (M12 family) }\end{array}$ & 4.6 & Yes & $\begin{array}{l}>5 \mathrm{~kb} \text { upstream of TSS; } 3^{\prime} \text { end, } \\
>5 \mathrm{~kb} \text { downstream of Exon } 10\end{array}$ \\
\hline Magee2a & Melanoma antigen, family E, 2 & 4.3 & No & Not applicable \\
\hline Tuba3aa & Tubulin, alpha $3 \mathrm{~A}$ & 4.3 & No & Not applicable \\
\hline LOC502684 & Hypothetical protein LOC502684 & 3.5 & Yes & $>10 \mathrm{~kb}$ upstream of TSS \\
\hline$C p / x 4^{a}$ & Complexin 4 & 3.4 & Yes & $\begin{array}{c}3^{\prime} \text { end; }>15 \mathrm{~kb} \text { downstream of } \\
\text { Exon } 3\end{array}$ \\
\hline$K c n v 2^{\mathrm{b}}$ & $\begin{array}{l}\text { Potassium channel, subfamily } \mathrm{V}, \\
\text { member } 2\end{array}$ & 3.2 & Yes & Exon 1 \\
\hline \multicolumn{5}{|c|}{ Downregulated genes } \\
\hline Olr1229 & Olfactory receptor 1229 & -17.6 & No & Not applicable \\
\hline Olr791 & Olfactory receptor 791 & -9.8 & No & Not applicable \\
\hline Fam46da & $\begin{array}{l}\text { Family with sequence similarity } 46, \\
\text { member } D\end{array}$ & -8.5 & No & Not applicable \\
\hline Olr788 & Olfactory receptor 788 & -7.3 & No & Not applicable \\
\hline Olr984 & Olfactory receptor 984 & -7.0 & No & Not applicable \\
\hline Olr750 & Olfactory receptor 750 & -6.6 & No & Not applicable \\
\hline Olr51 & Olfactory receptor 51 & -6.6 & No & Not applicable \\
\hline Ccr9a & Chemokines ( $\mathrm{C}-\mathrm{C}$ motif) receptor 9 & -6.4 & No & Not applicable \\
\hline Car7b & Carbonic anhydrase 7 & -6.2 & Yes & 5' promoter; TSS; Exon 1 \\
\hline Olr830 & Olfactory receptor 830 & -6.0 & No & Not applicable \\
\hline
\end{tabular}

Genome-wide transcription analysis on laser capture microdissected epithelia of PND21 mammary glands identified 504 differentially expressed genes $(P<0.05)$ between high-butterfat (HBF)-alone and HBF + bisphenol A (BPA, $25 \mu \mathrm{g} / \mathrm{kg}$ body weight/day) diet groups. The top ten differentially up- and downregulated genes are listed.

aRat genes that are homologous to human genes; bgenes with a promoter CG-rich region analyzed using bisulfite sequencing analysis; cthe presence and location of the putative regulatory CpG island were predicted by the UCSC Genome Browser.

TSS, transcription start site.

A

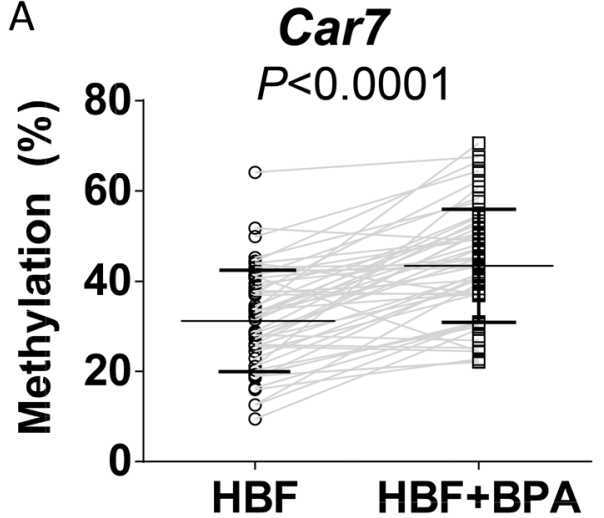

B Kcnv2

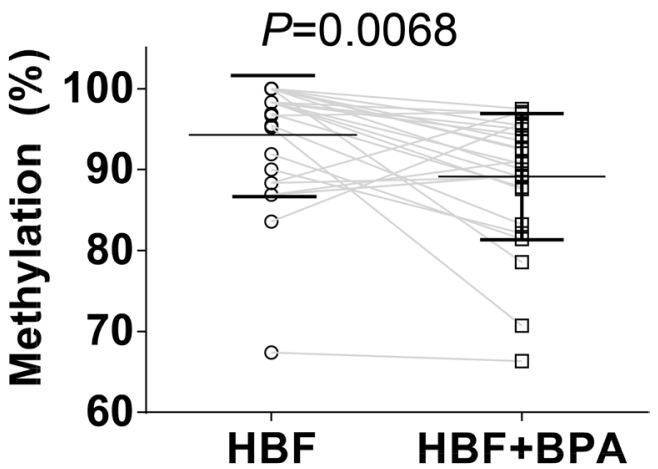

Figure 4

In utero high butterfat and BPA exposure alters DNA methylation level of the CpG island in Kcnv2 and Car7. Bisulfite-genomic sequencing was conducted to interrogate differential DNA methylation in (A) Car7 and (B) Kcnv2, in PND21 mammary glands of offspring fed a HBF diet vs a HBF diet with $25 \mu \mathrm{g} / \mathrm{kg}$ BW/day BPA. Percentage of methylation sites in the CpG island of Car7 (53 CpG sites) and Kcnv2 (27 CpG sites) were calculated. Each dot represents the average methylation percentage of each site. Mean (middle bar) and standard deviation (upper and lower bars) are represented in each group. Two-way ANOVA was performed to determine the difference between two groups. 
of gene expression as shown in the qPCR experiments (Supplementary Fig. 2).

\section{Top HBF BFBPA-dysregulated genes are associated with poor overall survival in TCGA breast cancer cohort}

To gain clinical significance, using The Cancer Genomic Atlas (TCGA) breast cancer cohort, we dichotomized 1082 breast cancer subjects into two groups based on the expression of the seven genes (ALDH1B1, ASTL, CA7, CPLX4, KCNV2, MAGEE2 and TUBA3E). As it is yet to be determined whether the identified top dysregulated genes are involved in human breast cancer, we selected seven out of the 12 that were clearly defined in humans for survival data analysis in TCGA cohort. Interestingly, we found those seven genes can be used to predict a group of 655 patients (Group 2, Fig. 5 left panel) with poor overall survival in the cohort $(P=0.0201)$. Stratifications on race and patients with estrogen receptor (ER)-positive tumors showed that these seven genes have a better prognostic value in Caucasian patients $(P=0.00368$, Fig. 5 middle panel) as well as in Caucasian patients with ER-positive breast cancer $(P=0.00033$, Fig. 5 right panel). Further analysis of Caucasian patients with ER-positive breast cancer suggested that the patients with poor overall survival (Group 2) have significantly less progesterone receptor expression (odds ratio $=3.682, P<0.0001$ ). All other parameters examined including age, lymph node positivity, cancer stage and cancer recurrence showed no statistical difference between the two groups of patients. Interestingly, expression of four genes (ALDH1B1, ASTL,
$C A 7$ and TUBA3E) of the seven gene panel was significantly different between the two groups of human breast cancer subjects (data not shown). The most significantly differentially expressed human genes (ASTL and TUBA3E) were also found to be upregulated in the poor overall survival group, similar to that of $\mathrm{Astl}$ and Tuba3a in rat mammary glands of the $\mathrm{HBF}+\mathrm{BPA}$ group.

\section{Discussion}

The primary aim of this study was to determine if maternal exposure to low doses of BPA $(2.5-2500 \mu \mathrm{g} / \mathrm{kg} \mathrm{BW} /$ day $)$ in combination with a HBF diet modifies mammary gland development and increases the risk of mammary tumorigenesis in first-generation offspring. Our major findings were that as a result of gestational intake of a diet containing $39 \% \mathrm{kcal}$ from butterfat, exposure to $\mathrm{BPA}$ at $25 \mu \mathrm{g} / \mathrm{kg} \mathrm{BW} /$ day was most effective in increasing mammary tumor incidence to $90 \%$ compared with $45.5 \%$ when BPA was not present in the diet. The doseresponse curve was non-monotonic and the effective dose was 200-fold and 2000-fold lower than the current no-observed adverse effect level (NOAEL; $5 \mathrm{mg} / \mathrm{kgBW} /$ day) and the lowest-observed adverse effect level (LOAEL; $50 \mathrm{mg} / \mathrm{kgBW} /$ day), respectively, as established by the US Environmental Protection Agency (EPA) (Agency USEP 2010). Mammary tumor incidence data correlated with significant increases in TEBs observed for the two lowest doses (2.5 and $25 \mu \mathrm{g} / \mathrm{kgBW} /$ day). In fact, in the present study, the BPA dose $(25 \mu \mathrm{g} / \mathrm{kg}$ BW/day $)$ that elicited the greatest mammary tumor incidence is 2 -fold less than the
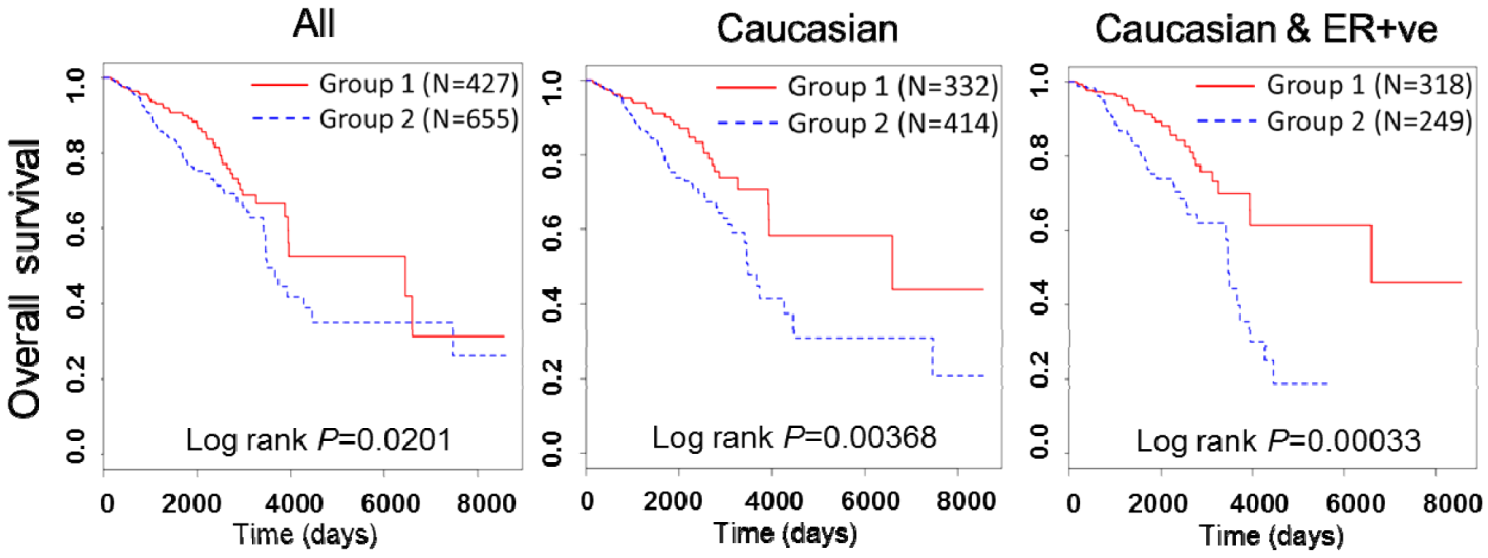

Figure 5

Top high butterfat + bisphenol A-dysregulated genes are associated with poor overall survival in breast cancer patients. Seven differentially expressed BPA genes in TCGA RNA-seq expression data were used to stratify a TCGA breast cancer cohort into two groups using unbiased hierarchical clustering. Survival analyses with log-rank test as well as multivariate survival analyses with Cox's regression model (adjusted with age at pathological analysis) based on overall survival data available in TCGA were performed. Patients in Group 1 show significantly better overall survival in all patients (left panel), Caucasian patients (middle panel) and Caucasian patients with ER-positive tumors (right panel) compared with group 2. 
US EPA's daily tolerable oral reference dose of $50 \mu \mathrm{g} / \mathrm{kg} \mathrm{BW} /$ day for human exposure (Agency USEP 2010), while the lowest effective dose causing increased mammary TEBs is 20-fold lower than the tolerance dose for humans.

In rodent models, BPA has been reported to alter the development of the mammary gland at the biochemical, cellular and tissue levels of organization, in manners suggestive of a heightened risk for mammary carcinogenesis (Markey et al. 2001, Munoz-de-Toro et al. 2005, Durando et al. 2007). Betancourt and coworkers (Betancourt et al. 2010) reported that a prenatal BPA dose of either 25 or $250 \mu \mathrm{g} / \mathrm{kg} \mathrm{BW} /$ day together with a standard diet had no tumorigenic effect after DMBA exposure at PND50. However, DMBA-induced carcinogenesis at PND100 resulted in a significantly increased number of terminal ducts (Moral et al. 2008) as well as a higher incidence of mammary tumors in rats exposed prenatally to $250 \mu \mathrm{g} / \mathrm{kgBW} /$ day BPA (Betancourt et al. 2010), suggesting that BPA at $250 \mu \mathrm{g} / \mathrm{kg} \mathrm{BW} /$ day could potentially shift the window of susceptibility for chemically induced mammary cancer from PND50 to PND100. To the best of our knowledge, no previous studies have investigated the impact of maternal consumption of a HBF diet together with BPA exposure on breast cancer risk in offspring. In our current study, we observed that concurrent BPA $(25 \mu \mathrm{g} / \mathrm{kg} \mathrm{BW} /$ day) exposure with a HBF diet background significantly increases mammary tumor incidence in female offspring treated with DMBA at PND50. We also observed significant increases in the number of TEBs in the mammary glands of PND21 rats born to dams fed a HBF diet and 2.5 or $25 \mu \mathrm{g} / \mathrm{kg}$ BW/day BPA during pregnancy. These effective BPA doses that alter mammary gland morphology and cancer susceptibility are 100-fold or 10 -fold, respectively, lower than the $250 \mu \mathrm{g} / \mathrm{kg} \mathrm{BW} /$ day BPA dose in the previously reported study (Betancourt et al. 2010). Additionally, under the HBF diet, the window of susceptibility to DMBA-induced carcinogenesis was reversed back to PND50 in our study. Perhaps, the HBF diet prevents the window-shifting effect caused by BPA, which may make the mammary glands more vulnerable to lower doses of BPA. In addition, independent studies of prenatal exposure to BPA or high-fat diets have observed alterations in the pace at which mammary gland differentiation occurs at different stages of development (Betancourt et al. 2010, Hilakivi-Clarke et al. 2013, Soto \& Sonnenschein 2015). Generally, perinatal administration of EDCs causes accelerated development of the mammary gland associated with increased proliferation and a higher number of TEBs at PND21 (Hovey et al. 2005).
Therefore, a greater availability of target structures, in addition to a cellular microenvironment favoring carcinogenesis, could explain the increased tumorigenic response (Russo \& Russo 1987, Hilakivi-Clarke 2007, de Oliveira Andrade et al. 2014).

Contrary to our expectation, we did not observe a higher mammary tumor risk in female offspring born to dams consuming a HBF diet (39\% kcal) alone during pregnancy when compared with those born to dams fed an AIN-93G control diet (10\% kcal). Furthermore, a trend of reduced mammary tumor incidence $(45 \%)$ in the offspring exposed in utero to a HBF diet vs an AIN-93G control diet (60\%) also correlated with a trend of reduced TEB count. Taken together, these findings suggest that offspring born to dams fed a HBF diet were at a reduced risk of developing mammary tumors following DMBA treatment at PND50. Our results are consistent with a previous study (de Oliveira Andrade et al. 2014), which observed that exposure to a lard-based high-fat diet during fetal and lactation periods decreases mammary cancer susceptibility in adulthood in rats. Although the source of high fat differed between studies, the fatty acid profile of the high-fat diet used in both studies consisted of saturated (mainly palmitic (16:0) and stearic acids (C18:0)) and monounsaturated (mainly oleic acid (18:1 n-9)) fatty acids, comprising $37 \%$ and $38 \%$ total fatty acids, respectively (de Oliveira Andrade et al. 2014). This is in contrast to published studies that associate in utero exposure to a corn oil-based high-fat diet alone, which contains polyunsaturated fatty acids, with an increased susceptibility to mammary tumorigenesis among female offspring (Hilakivi-Clarke et al. 1997, de Assis et al. 2006, 2012). These results suggest that future studies focusing on dietary fat composition during pregnancy are warranted.

Diet is estimated to contribute to the etiology of $30-50 \%$ of all breast cancers; however, the mechanism(s) by which dietary patterns or EDCs modify breast cancer risk is not fully understood (Holmes \& Willett 2004, Adebamowo etal.2005, Hilakivi-Clarke 2007). In this study, we showed that gestational exposure to BPA with HBF diet intake dysregulates early cancer-related gene expression even before cancer development, implying that the EDC predisposes cancer risk by reprogramming gene expression in mammary glands. Some of these dysregulated gene events are mediated through epigenetics, DNA methylation in particular. We and others found that alterations in the fetal environment have caused persistent modification in gene expression and susceptibility of disease (Ho et al. 2006, 
Hilakivi-Clarke 2007). Maternal exposure to BPA during pregnancy increases offspring's risk of prostate cancer and induces hypomethylation of phosphodiesterase type 4 variant 4 (PDE4D4), an enzyme responsible for cyclic AMP breakdown (Ho et al. 2006). Furthermore, a highfat- or ethinyl-estradiol-supplemented maternal diet has been shown to increase mammary cancer risk in several generations of offspring and is associated with changes in the DNA methylation machinery and methylation patterns in mammary tissue (de Assis et al. 2012). In the present study, we observed significant change in the methylation status of the promoter region of Car7 and Kcnv2, concomitantly with significant change in their gene expression level, although both genes have never been reported to be breast cancer related in humans. CA7, carbonic anhydrase VII, catalyzes the hydration of carbon dioxide into bicarbonate and proton. It is one of the active isoforms found in cytosolic compartment. Although the mechanistic role of $C A 7$ in cancer is not much known, it has been speculated that the absence of the antioxidant property of $C A 7$ could contribute to disease progression (Monti et al. 2017). Its tumor-suppressive potential was identified in colorectal cancer as reduced CA7 level was associated with shorter disease-specific survival (Yang et al. 2015). KCNV2, voltage-gated $\mathrm{K}+$ channel subunit gene family $\mathrm{V}$ member 2 , can form functional heterotetramers with Kv2 subunits and influence membrane translocation and channel properties (Ottschytsch et al. 2002, Czirjak et al. 2007). Its role in cancer is largely unclear and only its close relative, Kv9.3, was known to support the growth of colon, lung and uterine cancer cells (Suzuki \& Takimoto 2004, Spitzner et al. 2007, Lee et al. 2015). We also found that a group of olfactory genes in the mammary gland of PND21 female offspring were downregulated in $\mathrm{HBF}+\mathrm{BPA}$ group when compared with HBF only. Interestingly, the fetal gene expression profile of olfactory receptors has been shown to be modulated by slight nutrient changes in the maternal diet (Rosenfeld 2012).

Altered expression of genes involved in promoting cell proliferation in the offspring's mammary gland during development of offspring exposed to maternal dietary fat have been found to increase susceptibility to cancer in adulthood (Hilakivi-Clarke 2007). Using Ingenuity Pathway Analysis, we identified the top biological processes related to the identified dietary exposureassociated genes to include 'Cancer, Cellular development, Embryonic development' and 'Gene expression, Cancer, and Organismal injury and Abnormalities'. One was associated with ERK rapid signaling and the other was related to AR. When these networks were merged, AR was the key node for the two cancer-related networks, suggesting that aberrant activation of these signaling pathways may play a key role in adult mammary tumor risk. Interestingly, recent investigations have identified the AR signaling pathway as a target for breast cancer treatment, with several clinical trials currently ongoing (Pietri et al. 2016).

In this study, we identified $\mathrm{HBF}+\mathrm{BPA}$-related gene dysregulation in developing mammary glands. Although we cannot rule out in the current study that BPA, in the context of a control diet, may dysregulate some of the same $\mathrm{HBF}+\mathrm{BPA}$-related genes, offspring exposed to a control diet showed no significant difference in mammary tumor incidence in the absence vs presence of $25 \mu \mathrm{g} / \mathrm{kg}$ BW/day BPA. Pathway analyses suggested that the majority of the identified HBF + BPA-related genes are classified as 'cancer' associated, but little information has been reported about their roles in cancer development. We took advantage of the publicly available RNA-seq and survival data from TCGA and determined that seven differentially expressed genes (ALDH1B1, ASTL, CA7, CPLX4, KCNV2, MAGEE2 and TUBA3E) could be involved in breast cancer development, especially in Caucasian female patients with ER positivity. It is intriguing to see that the 'signature', which is composed of 7 genes, could be a significant prognostic indicator for breast cancer patients even though the role of each gene in breast cancer remains largely unknown. Therefore, genomewide data together with patient-based survival analyses provide an effective way to reveal novel genes/pathways involved in cancer development. However, how those genes are linked to ER signaling and whether those genes functions as oncogenes or tumor suppressor genes in a specific genetic background require more detailed investigation in future.

In conclusion, our data reinforce findings that maternal diet during pregnancy can determine the susceptibility of offspring to the development of breast cancer in adult life (Hilakivi-Clarke 2007, de Assis et al. 2012, de Oliveira Andrade et al. 2014). Importantly, we found that concurrent exposure to a HBF diet and BPA below the current NOAEL during pregnancy modulates developmental morphology and gene expression in the prepubertal mammary gland and increases the breast cancer incidence in offspring. It is apparent from our findings that the complex interplay of diet and environmental exposure to an endocrine disrupter can reprogram the developing mammary gland permitting a permissive environment for adult breast cancer risk in the first-generation offspring.

Published by Bioscientifica Ltd. 


\section{Supplementary data}

This is linked to the online version of the paper at http://dx.doi.org/10.1530/ ERC-17-0006

\section{Declaration of interest}

The authors declare that there is no conflict of interest that could be perceived as prejudicing the impartiality of the research reported.

\section{Funding}

This study was supported in part by grants from the National Institutes of Health: U01ES019480, U01ES020988, U54HL127624, RC2ES018765, P30ES006096 and P30ES025128, and the United States Department of Veterans Affairs: I01BX000675.

\section{Author contribution statement}

Experimental design: $Y K L, G$ V, S B and $S M H$; performing experiments: Y K L, G V, A C, D S, X Z, A K, R G; data analyses: Y K L, G V, A C, D S, X Z, J $Y, M M, S M H$; writing manuscript: $Y K L, G V, A C$, J V, J Y, A K, M M, S M H.

\section{Acknowledgements}

Special thanks to Huan $\mathrm{Xu}$ for providing initial technical support for RNA-seq data analyses and Dr Neville Tam for technical assistance in cryosectioning of the samples.

\section{References}

Adebamowo CA, Hu FB, Cho E, Spiegelman D, Holmes MD \& Willett WC 2005 Dietary patterns and the risk of breast cancer. Annals of Epidemiology 15 789-795. (doi:10.1016/j.annepidem.2005.01.008) Agency USEP 2010 Bisphenol A Action Plan (CASRN 80-05-7).

Betancourt AM, Eltoum IA, Desmond RA, Russo J \& Lamartiniere CA 2010 In utero exposure to bisphenol A shifts the window of susceptibility for mammary carcinogenesis in the rat. Environmental Health Perspectives 118 1614-1619. (doi:10.1289/ehp.1002148)

Buell P 1973 Changing incidence of breast cancer in Japanese-American women. Journal of the National Cancer Institute 51 1479-1483. (doi:10.1093/jnci/51.5.1479)

Cho E, Spiegelman D, Hunter DJ, Chen WY, Stampfer MJ, Colditz GA \& Willett WC 2003 Premenopausal fat intake and risk of breast cancer. Journal of the National Cancer Institute 95 1079-1085. (doi:10.1093/ jnci/95.14.1079)

Czirjak G, Toth ZE \& Enyedi P 2007 Characterization of the heteromeric potassium channel formed by kv2.1 and the retinal subunit kv8.2 in Xenopus oocytes. Journal of Neurophysiology 98 1213-1222. (doi:10.1152/jn.00493.2007)

de Assis S, Khan G \& Hilakivi-Clarke L 2006 High birth weight increases mammary tumorigenesis in rats. International Journal of Cancer 119 1537-1546. (doi:10.1002/ijc.21936)

de Assis S, Warri A, Cruz MI, Laja O, Tian Y, Zhang B, Wang Y, Huang TH \& Hilakivi-Clarke L 2012 High-fat or ethinyl-oestradiol intake during pregnancy increases mammary cancer risk in several generations of offspring. Nature Communications 3 1053. (doi:10.1038/ncomms2058)

de Oliveira Andrade F, Fontelles CC, Rosim MP, de Oliveira TF, de Melo Loureiro AP, Mancini-Filho J, Rogero MM, Moreno FS, de Assis S, Barbisan LF, et al. 2014 Exposure to lard-based high-fat diet during fetal and lactation periods modifies breast cancer susceptibility in adulthood in rats. Journal of Nutritional Biochemistry 25 613-622. (doi:10.1016/j.jnutbio.2014.02.002)

Doherty LF, Bromer JG, Zhou Y, Aldad TS \& Taylor HS 2010 In utero exposure to diethylstilbestrol (DES) or bisphenol-A (BPA) increases EZH2 expression in the mammary gland: an epigenetic mechanism linking endocrine disruptors to breast cancer. Hormones and Cancer $\mathbf{1}$ 146-155. (doi:10.1007/s12672-010-0015-9)

Durando M, Kass L, Piva J, Sonnenschein C, Soto AM, Luque EH \& Munoz-de-Toro M 2007 Prenatal bisphenol A exposure induces preneoplastic lesions in the mammary gland in Wistar rats. Environmental Health Perspectives 115 80-86. (doi:10.1289/ ehp.9282)

Fabian CJ, Kimler BF \& Hursting SD 2015 Omega-3 fatty acids for breast cancer prevention and survivorship. Breast Cancer Research 1762. (doi:10.1186/s13058-015-0571-6)

Gonzalez CA \& Riboli E 2010 Diet and cancer prevention: contributions from the European Prospective Investigation into Cancer and Nutrition (EPIC) study. European Journal of Cancer 46 2555-2562. (doi:10.1016/j.ejca.2010.07.025)

Govindarajah V, Leung YK, Ying J, Gear R, Bornschein RL, Medvedovic M \& Ho SM 2016 In utero exposure of rats to high-fat diets perturbs gene expression profiles and cancer susceptibility of prepubertal mammary glands. Journal of Nutritional Biochemistry 29 73-82. (doi:10.1016/j.jnutbio.2015.11.003)

Hanf V \& Gonder U 2005 Nutrition and primary prevention of breast cancer: foods, nutrients and breast cancer risk. European Journal of Obstetrics Gynecology and Reproductive Biology 123 139-149. (doi:10.1016/j.ejogrb.2005.05.011)

Heffelfinger SC, Gear RB, Schneider J, LaDow K, Yan M, Lu F, Pyle AL \& Warshawsky D 2003 TNP-470 inhibits 7,12-dimethylbenz[a] anthracene-induced mammary tumor formation when administered before the formation of carcinoma in situ but is not additive with tamoxifen. Laboratory Investigation 83 1001-1011. (doi:10.1097/01. LAB.0000075641.27128.67)

Hilakivi-Clarke L 2007 Nutritional modulation of terminal end buds: its relevance to breast cancer prevention. Current Cancer Drug Targets 7 465-474. (doi:10.2174/156800907781386641)

Hilakivi-Clarke L, Cho E, Raygada M, Onojafe I, Clarke R \& Lippman ME 1995 Early life affects the risk of developing breast cancer. Annals of the New York Academy of Sciences 768 327-330. (doi:10.1111/j.1749-6632.1995.tb12152.x)

Hilakivi-Clarke L, Onojafe I, Raygada M, Cho E, Clarke R \& Lippman ME 1996 Breast cancer risk in rats fed a diet high in n-6 polyunsaturated fatty acids during pregnancy. Journal of the National Cancer Institute 88 1821-1827. (doi:10.1093/jnci/88.24.1821)

Hilakivi-Clarke L, Clarke R, Onojafe I, Raygada M, Cho E \& Lippman M 1997 A maternal diet high in n-6 polyunsaturated fats alters mammary gland development, puberty onset, and breast cancer risk among female rat offspring. PNAS 94 9372-9377. (doi:10.1073/ pnas.94.17.9372)

Hilakivi-Clarke L, Clarke R \& Lippman M 1999 The influence of maternal diet on breast cancer risk among female offspring. Nutrition 15 392-401. (doi:10.1016/S0899-9007(99)00029-5)

Hilakivi-Clarke L, Cho E, Cabanes A, DeAssis S, Olivo S, Helferich W, Lippman ME \& Clarke R 2002 Dietary modulation of pregnancy estrogen levels and breast cancer risk among female rat offspring. Clinical Cancer Research 8 3601-3610.

Hilakivi-Clarke L, de Assis S \& Warri A 2013 Exposures to synthetic estrogens at different times during the life, and their effect on breast cancer risk. Journal of Mammary Gland Biology and Neoplasia 18 25-42. (doi:10.1007/s10911-013-9274-8)

Ho SM, Tang WY, Belmonte de Frausto J \& Prins GS 2006 Developmental exposure to estradiol and bisphenol A increases susceptibility to prostate carcinogenesis and epigenetically regulates phosphodiesterase type 4 variant 4 . Cancer Research 66 5624-5632. (doi:10.1158/0008-5472.CAN-06-0516) 
Holmes MD \& Willett WC 2004 Does diet affect breast cancer risk? Breast Cancer Research 6 170-178. (doi:10.1186/bcr909)

Hovey RC, Asai-Sato M, Warri A, Terry-Koroma B, Colyn N, Ginsburg E \& Vonderhaar BK 2005 Effects of neonatal exposure to diethylstilbestrol, tamoxifen, and toremifene on the BALB/c mouse mammary gland. Biology of Reproduction 72 423-435. (doi:10.1095/ biolreprod.104.029769)

Hulka BS 1989 Dietary fat and breast cancer: case-control and cohort studies. Preventive Medicine 18 180-193. (doi:10.1016/00917435(89)90065-0)

Hunter DJ, Spiegelman D, Adami HO, Beeson L, van den Brandt PA, Folsom AR, Fraser GE, Goldbohm RA, Graham S, Howe GR, et al. 1996 Cohort studies of fat intake and the risk of breast cancer - a pooled analysis. New England Journal of Medicine 334 356-361. (doi:10.1056/NEJM199602083340603)

Key TJ, Appleby PN, Cairns BJ, Luben R, Dahm CC, Akbaraly T, Brunner EJ, Burley V, Cade JE, Greenwood DC, et al. 2011 Dietary fat and breast cancer: comparison of results from food diaries and foodfrequency questionnaires in the UK Dietary Cohort Consortium. American Journal of Clinical Nutrition 94 1043-1052. (doi:10.3945/ ajcn.111.015735)

Lee JH, Park JW, Byun JK, Kim HK, Ryu PD, Lee SY \& Kim DY 2015 Silencing of voltage-gated potassium channel KV9.3 inhibits proliferation in human colon and lung carcinoma cells. Oncotarget 6 8132-8143. (doi:10.18632/oncotarget.3517)

Livak KJ \& Schmittgen TD 2001 Analysis of relative gene expression data using real-time quantitative PCR and the 2(-Delta Delta C(T)) Method. Methods 25 402-408. (doi:10.1006/meth.2001.1262)

Lo CY, Hsieh PH, Chen HF \& Su HM 2009 A maternal high-fat diet during pregnancy in rats results in a greater risk of carcinogeninduced mammary tumors in the female offspring than exposure to a high-fat diet in postnatal life. International Journal of Cancer $\mathbf{1 2 5}$ 767-773. (doi:10.1002/ijc.24464)

Lof M, Sandin S, Lagiou P, Hilakivi-Clarke L, Trichopoulos D, Adami HO \& Weiderpass E 2007 Dietary fat and breast cancer risk in the Swedish women's lifestyle and health cohort. British Journal of Cancer 97 1570-1576. (doi:10.1038/sj.bjc.6604033)

MacLennan M \& Ma DW 2010 Role of dietary fatty acids in mammary gland development and breast cancer. Breast Cancer Research 12211. (doi:10.1186/bcr2646)

Markey CM, Luque EH, Munoz De Toro M, Sonnenschein C \& Soto AM 2001 In utero exposure to bisphenol A alters the development and tissue organization of the mouse mammary gland. Biology of Reproduction 65 1215-1223. (doi:10.1093/biolreprod/65.4.1215)

Martin LJ, Li Q, Melnichouk O, Greenberg C, Minkin S, Hislop G \& Boyd NF 2011 A randomized trial of dietary intervention for breast cancer prevention. Cancer Research 71 123-133. (doi:10.1158/00085472.CAN-10-1436)

Martinez AM, Cheong A, Ying J, Xue J, Kannan K, Leung YK, Thomas MA \& Ho SM 2015 Effects of high-butterfat diet on embryo implantation in female rats exposed to bisphenol A. Biology of Reproduction 93 147. (doi:10.1095/biolreprod.115.131433)

Medvedovic M, Gear R, Freudenberg JM, Schneider J, Bornschein R, Yan M, Mistry MJ, Hendrix H, Karyala S, Halbleib D, et al. 2009 Influence of fatty acid diets on gene expression in rat mammary epithelial cells. Physiological Genomics 38 80-88. (doi:10.1152/ physiolgenomics.00007.2009)

Monti DM, De Simone G, Langella E, Supuran CT, Di Fiore A \& Monti SM 2017 Insights into the role of reactive sulfhydryl groups of carbonic anhydrase III and VII during oxidative damage. Journal of Enzyme Inhibition and Medicinal Chemistry 32 5-12. (doi:10.1080/147 56366.2016.1225046)

Moral R, Wang R, Russo IH, Lamartiniere CA, Pereira J \& Russo J 2008 Effect of prenatal exposure to the endocrine disruptor bisphenol A on mammary gland morphology and gene expression signature. Journal of Endocrinology 196 101-112. (doi:10.1677/JOE-07-0056)
Munoz-de-Toro M, Markey CM, Wadia PR, Luque EH, Rubin BS, Sonnenschein C \& Soto AM 2005 Perinatal exposure to bisphenol-A alters peripubertal mammary gland development in mice. Endocrinology 146 4138-4147. (doi:10.1210/en.2005-0340)

Ottschytsch N, Raes A, Van Hoorick D \& Snyders DJ 2002 Obligatory heterotetramerization of three previously uncharacterized $\mathrm{Kv}$ channel alpha-subunits identified in the human genome. PNAS 99 7986-7991. (doi:10.1073/pnas.122617999)

Park SY, Kolonel LN, Henderson BE \& Wilkens LR 2012 Dietary fat and breast cancer in postmenopausal women according to ethnicity and hormone receptor status: the Multiethnic Cohort Study. Cancer Prevention Research 5 216-228. (doi:10.1158/1940-6207.CAPR-110260)

Perera F \& Herbstman J 2011 Prenatal environmental exposures, epigenetics, and disease. Reproductive Toxicology 31 363-373. (doi:10.1016/j.reprotox.2010.12.055)

Peto J 2001 Cancer epidemiology in the last century and the next decade. Nature 411 390-395. (doi:10.1038/35077256)

Pietri E, Conteduca V, Andreis D, Massa I, Melegari E, Sarti S, Cecconetto L, Schirone A, Bravaccini S, Serra P, et al. 2016 Androgen receptor signaling pathways as a target for breast cancer treatment. Endocrine-Related Cancer 23 R485-R498. (doi:10.1530/ ERC-16-0190)

Prentice RL, Caan B, Chlebowski RT, Patterson R, Kuller LH, Ockene JK, Margolis KL, Limacher MC, Manson JE, Parker LM, et al. 2006 Lowfat dietary pattern and risk of invasive breast cancer: the Women's Health Initiative Randomized Controlled Dietary Modification Trial. JAMA 295 629-642. (doi:10.1001/jama.295.6.629)

Rosenfeld CS 2012 Effects of maternal diet and exposure to bisphenol A on sexually dimorphic responses in conceptuses and offspring. Reproduction in Domestic Animals 47 (Supplement 4) 23-30. (doi:10.1111/j.1439-0531.2012.02051.x)

Russo IH \& Russo J 1978 Developmental stage of the rat mammary gland as determinant of its susceptibility to 7,12-dimethylbenz[a] anthracene. Journal of the National Cancer Institute 61 1439-1449.

Russo J \& Russo IH 1987 Biological and molecular bases of mammary carcinogenesis. Laboratory Investigation 57 112-137. (doi:10.1093/ jnci/61.6.1439)

Russo IH \& Russo J 1996a Mammary gland neoplasia in long-term rodent studies. Environmental Health Perspectives 104 938-967. (doi:10.1289/ehp.96104938)

Russo J \& Russo IH 1996b Experimentally induced mammary tumors in rats. Breast Cancer Research and Treatment 39 7-20. (doi:10.1007/ BF01806074)

Russo J, Wilgus G \& Russo IH 1979 Susceptibility of the mammary gland to carcinogenesis: I Differentiation of the mammary gland as determinant of tumor incidence and type of lesion. American Journal of Pathology 96 721-736.

Russo J, Tay LK, Ciocca DR \& Russo IH 1983 Molecular and cellular basis of the mammary gland susceptibility to carcinogenesis. Environmental Health Perspectives 49 185-199. (doi:10.1289/ ehp.8349185)

Soto AM, Brisken C, Schaeberle C \& Sonnenschein C 2013 Does cancer start in the womb? altered mammary gland development and predisposition to breast cancer due to in utero exposure to endocrine disruptors. Journal of Mammary Gland Biology and Neoplasia 18 199-208. (doi:10.1007/s10911-013-9293-5)

Soto AM \& Sonnenschein C 2015 Endocrine disruptors: DDT, endocrine disruption and breast cancer. Nature Reviews Endocrinology 11 507-508. (doi:10.1038/nrendo.2015.125)

Spitzner M, Ousingsawat J, Scheidt K, Kunzelmann K \& Schreiber R 2007 Voltage-gated $\mathrm{K}+$ channels support proliferation of colonic carcinoma cells. FASEB Journal 21 35-44. (doi:10.1096/fj.06-6200com)

Suzuki T \& Takimoto K 2004 Selective expression of HERG and Kv2 channels influences proliferation of uterine cancer cells. International Journal of Oncology 25 153-159. 
Teegarden D, Romieu I \& Lelievre SA 2012 Redefining the impact of nutrition on breast cancer incidence: is epigenetics involved? Nutrition Research Reviews 25 68-95. (doi:10.1017/S0954422411000199)

Thigpen JE, Setchell KD, Kissling GE, Locklear J, Caviness GF, Whiteside T, Belcher SM, Brown NM, Collins BJ, Lih FB, et al. 2013 The estrogenic content of rodent diets, bedding, cages, and water bottles and its effect on bisphenol A studies. Journal of the American Association for Laboratory Animal Science 52 130-141.

Welsch CW 1985 Host factors affecting the growth of carcinogeninduced rat mammary carcinomas: a review and tribute to Charles Brenton Huggins. Cancer Research 45 3415-3443.

Willett WC, Hunter DJ, Stampfer MJ, Colditz G, Manson JE, Spiegelman D, Rosner B, Hennekens CH \& Speizer FE 1992 Dietary fat and fiber in relation to risk of breast cancer. An 8-year follow-up. JAMA $\mathbf{2 6 8}$ 2037-2044. (doi:10.1001/jama.1992.03490150089030)
Yang GZ, Hu L, Cai J, Chen HY, Zhang Y, Feng D, Qi CY, Zhai YX, Gong $\mathrm{H}, \mathrm{Fu} \mathrm{H}$, et al. 2015 Prognostic value of carbonic anhydrase VII expression in colorectal carcinoma. BMC Cancer 15209. (doi:10.1186/s12885-015-1216-y)

Zhu X, Leav I, Leung YK, Wu M, Liu Q, Gao Y, McNeal JE \& Ho SM 2004 Dynamic regulation of estrogen receptor-beta expression by DNA methylation during prostate cancer development and metastasis. American Journal of Pathology 164 2003-2012. (doi:10.1016/S0002-9440(10)63760-1)

Ziegler RG, Hoover RN, Pike MC, Hildesheim A, Nomura AM, West DW, Wu-Williams AH, Kolonel LN, Horn-Ross PL, Rosenthal JF, et al. 1993 Migration patterns and breast cancer risk in Asian-American women. Journal of the National Cancer Institute 85 1819-1827. (doi:10.1093/ jnci/85.22.1819)

Received in final form 3 May 2017

Accepted 8 May 2017

Accepted Preprint published online 9 May 2017
Published by Bioscientifica Ltd. 